\title{
Association between PD-L1 expression and head and neck cancer prognosis: a meta-analysis
}

\author{
Zhisen Shen ( $\nabla$ szs7216@163.com ) \\ Ningbo Medical Treatment Centre Li Huili Hospital \\ Linrong Wu \\ Ningbo Medical Treatment Centre Li Huili Hospital \\ Xianlei Cai \\ Ningbo Medical Treatment Centre Li Huili Hospital \\ Dong Ye \\ Ningbo Medical Treatment Centre Li Huili Hospital \\ Gangjun Zhao \\ Ningbo Medical Treatment Centre Li Huili Hospital
}

\section{Research article}

Keywords: programmed cell death ligand 1, head and neck cancer, prognosis, overall survival, meta-analysis

Posted Date: August 14th, 2019

DOI: https://doi.org/10.21203/rs.2.12808/v1

License: (c) (i) This work is licensed under a Creative Commons Attribution 4.0 International License. Read Full License 


\section{Abstract}

Background: Programmed cell death ligand 1هPD-L1) plays an important role in tumor cell immune escape, and it has been extensively studied in head and neck cancer. However, its prognostic impact on patients with head and neck cancer remains controversial, so we sought to investigate this issue through a comprehensive meta-analysis.

Methods: To assess the significance of PD-L1 on the survival of patients with head and neck cancer, we collected articles reported in PubMed, EMBASE, and Cochrane Library, until January 31, 2019. We also used the Newcastle Ottawa Scale (NOS) for literature quality evaluation.

Results: The study included a total of 4551 patients affected by 6 different types of head and neck cancer reported in 26 articles. Our study found that the association between the expression of PD-L1 and the prognosis of head and neck tumors was highly heterogeneous $(P<0.00001,12=80.0 \%)$; therefore, the random effects model was applied to combine the effect sizes. Based on the combined hazard ratios (HR)of 1.15 (95\% Cl: 0.88 to $1.50, P=0.32$ ), the expression of PD-L1 in head and neck tumors may not be a factor associated with poor prognosis.

Conclusions: Our results suggest that PD-L1 expression cannot predict the overall survival of patients with oral, nasopharyngeal, or esophageal cancer. Through subgroup analysis, we found that the expression of PD-L1 may be a poor prognostic factor for some head and neck cancers.

\section{Background}

Head and neck cancer (HNC) is the sixth most common cancer in the world [1].More than 500,000 people worldwide are diagnosed with HNC each year, and approximately 380,000 people die from this disease each year [2].HNC may affect the nasopharynx, oropharynx, oral cavity, larynx, hypopharyngeal and esophageal cavity, nasal and paranasal cavity, temporal bone, salivary glands and so on, and most of these subtypes are squamous cell carcinoma. The global incidence of HNC has been increasing for decades, but the reasons are not fully understood [3].Due to the absence of early symptoms and lack of effective screening techniques, most patients are diagnosed with advanced cancer [1].

Programmed death factor $1(P D-1)$ and its ligands are currently one of the research focuses of tumor targeted therapy. When PD-1 binds to the ligand PD-L1, the function of T cells is reduced by various mechanisms, including antagonizing $T$ cell receptors to inhibit their signal transduction, changing the normal metabolism of $T$ cells to inhibit their differentiation, and reducing the antioxidant function of $T$ cells to inhibit their killing [4,5]. At present, several PD-1 inhibitors and PD-L1 inhibitors have entered clinical trials, and some are used in cancer treatment. Nivolumab was the first PD-L1 inhibitor to be marketed and approved by the FDA for the treatment of metastatic melanoma, non-small cell lung cancer and advanced renal cell carcinoma [6].

To better prolong the survival of patients with HNC, the selection of effective immunological molecular biomarkers and immunotherapy programs will open up new strategies for the treatment of advanced HNC. 
Many studies have found that high expression of PD-L1 in HNC patients is associated with poor prognosis and does not depend on the tumor origin. PD-L1 is considered to be a prognostic biomarker [7]. Therefore, we conducted this meta-analysis to determine the prognostic impact of PD-L1 on patients with HNC.

\section{Method}

\section{Search method}

All articles were searched in the PubMed, EMBASE, and Cochrane Library databases, up to January 31, 2019. We used the search terms ("head and neck tumor" OR "oral” OR "tonsil" OR "parathyroid" OR "thyroid" OR “laryngeal” OR "ear" OR "nose” OR “tongue” OR "salivary gland” OR "esophageal” OR "facial” OR "nasopharyngeal" OR "hypopharyngeal") and ("pd-I1" OR "b7-h1"OR "programmed death ligand 1" OR "cd274" OR "b7homolog1" OR "pdl1") and ("cancer" OR “carcinoma” OR "adenocarcinoma”). Selected publications were all written in the English language. In addition, the references included in the articles were manually reviewed to obtain other potentially relevant articles.

\section{Inclusion criteria}

The inclusion criteria included that the clinical and pathological data of all cases were complete, and the pathological examination confirmed the diagnosis of HNC. Additionally, immunohistochemistry (IHC) staining for the detection of PD-L1 expression in tumor tissues, and raw data about PD-L1 expression and $\mathrm{HR}$ and $95 \% \mathrm{Cl}$ for the prognostic correlation in cancer patients were provided in the study.

\section{Exclusion criteria}

The exclusion criteria consisted of non-original research articles, such as reviews, abstracts, letters, and case reports; copying reports or similar data; Newcastle-Ottawa Scale (NOS) scores $<5$ points and other unusable documents; the subjects were not human patients; the sample size was less than 30 ; and the full text could not be obtained.

\section{Data extraction}

Data extraction and quality assessment were performed by two of the authors. The data included in each study were extracted independently. The authors extracted the author's name, publication year, country in which the study was conducted, sample size, cancer type, and critical criteria for over expression (the definition of positive PD-L1), hazard ratios (HRs) and 95\% confidence intervals (CI).

\section{Quality assessment}

According to the NOS, the quality of each of the included studies was evaluated [8].The total score was 9 points, and articles with scores below 5 points were deemed to be of low-quality. The evaluation process 
was independently conducted by 2 authors, and differences in evaluation were resolved by negotiation. When the opinions were inconsistent, a 3rd author made the assessment. Finally, the appropriate literature was selected for meta-analysis.

\section{Statistical analysis}

$\mathrm{HR}$ and $\mathrm{Cl}$ were used to assess the association between PD-L1 expression levels and head and neck tumor prognosis. Heterogeneity testing was performed using Revman 5.3 software. The Chi-square test was to estimate the between-study heterogeneity. When $P \geq 0.1$ and $I^{2} \leq 50 \%$, the studies were considered homogeneous, and the fixed effect model was selected and analyzed. When $P<0.1$ and $I^{2}>50 \%$, the studies were considered to be heterogeneous, and the source of heterogeneity was further analyzed by subgroup analysis or sensitivity analysis. If the heterogeneity could not be eliminated, the random effects model was chosen. Additionally, a funnel plot was drawn to test the publication bias of the assessment study [9].

\section{Results}

\section{Description of trials included in the meta-analysis}

A total of 320 articles were retrieved from the relevant databases, all the documents were saved to Endnote and evaluated, and 111 duplicates were excluded. After reading the titles and abstracts of the articles, 80 preliminary screenings were obtained. After reading the full text, according to the inclusion and exclusion criteria, 26 articles were selected [10-35], which included 4551 patients. The flow diagram of literature selection is summarized in Fig. 1. Twenty-six articles were used for meta-analysis of the survival data. The quality of the literature was evaluated according to the NOS, and only articles with 5 points or more were included. The vast majority of the studies were based on Asian populations, including 13 Chinese population studies, 3 Japanese population studies, and 4 Korean population studies; the sample size of 7 studies was below 100, and the sample size of 19 studies was greater than 100 . There were 7 studies on nasopharyngeal carcinoma, 6 on oral cancer, 8 on esophageal cancer, and 2 on thyroid cancer. The indicators of 23 studies were overall survival (OS), and the other three were progression-free survival (PFS), disease-free survival (DFS), disease-specific survival (DSS), The characteristics of the included studies are summarized in Table 1.

\section{Prognosis}

A total of 26 studies reported that the levels of PD-L1 expression were associated with prognosis. Twelve studies showed that PD-L1 over expression is associated with poor prognosis in HNC. Our analysis showed that the expression level of PD-L1 was not associated with prognosis in $\mathrm{HNC}(\mathrm{HR}=1.15,95 \% \mathrm{Cl}=0.88-$ 1.50, $P=0.32$, random effect) (Fig. 2).

\section{Subgroup analysis}


Further subgroup analysis was based on the patient's origin (China and not China), the IHC assessment of PD-L1 percentage cutoff, and the cancer type. The conclusions from the subgroup analysis were similar to those of the overall analysis (more details are listed in Table 3, 4 and 5.). However, we found that PD-L1 may be a poor prognosis factor for oral squamous cell carcinoma and other types of head and neck cancer.

FIGURE 3 Meta-analysis forest plot of the subgroups of HNC survival in different regions.

\section{Prognostic study publication bias and sensitive analysis}

The funnel plot test evaluated the publication bias. The result shows incomplete symmetry (Fig. 6), suggesting that there may be publication bias in the prognostic study. Sensitive analysis did not change the results.

\section{Discussion}

The study included a total of 4551 patients affected by 6 different types of head and neck cancer reported in 26 articles. Our study found that the association between PD-L1 expression and head and neck tumor prognosis is highly heterogeneous; therefore, a random effects model was applied. We found that the expression of PD-L1 in head and neck tumors may not be a factor in poor prognosis. Through subgroup analysis, we found that the expression of PD-L1 was not related with the prognosis of oral cancer, esophageal cancer, and nasopharyngeal carcinoma, but it may be a poor prognostic biomarker for other types of head and neck cancer.

Many meta-analyses report the prognostic value of PD-L1 in various types of cancer [36-39], and a large number of studies have reported the association between PD-L1 and the prognosis of head and neck tumors [10-35], but the results are not completely consistent. Therefore, this paper used a meta-analysis to explore the association between PD-L1 and HNC prognosis. Head and neck tumors consists mainly of head and neck squamous cell carcinoma. Recently, yang [40] reported that PD-L1 expression by IHC is not recommended as a predictor of HNSCC survival and that positive PD-L1 expression may predict better PFS in patients with advanced HNSCC. Our study collected more studies for meta-analysis to investigate the association between PD-L1 and HNC prognosis, and similar results were obtained. It should be emphasized that the heterogeneity of the results cannot be ignored. Heterogeneity may be due to different sample sizes of the included studies, the different relevant detection methods, including antibody selection, standardized definition of outcome indicators and differences in population characteristics and types and sources of cancer. The most important is the different standards for PD-L1 expression. During our research, we found that the cut-off value was not standardized. There are two ways to define the cut-off value in the study. One method is the integral comprehensive measurement method; the value corresponding to each positive intensity $x$ the percentage of the intensity cells, and then sum again. The second method is to use the value corresponding to the percentage of positive cells. Therefore, based on the cut-off value, we performed a subgroup analysis. We found that the heterogeneity of the cutoff group of $5 \%$ is small (Fig. 4). In addition, we performed a subgroup analysis based on the type of cancer and found that for other types of head and neck cancers, it seems that PD- L1 expression was associated with prognosis. 


\section{Conclusion}

Based on the above meta-analysis, we preliminarily estimated that the expression of PD-L1 may not be significantly related to the prognosis of oral squamous cell carcinoma, nasopharyngeal carcinoma, and esophageal squamous cell carcinoma. However, for some of other HNC, we cannot deny the existence of the correlation.

\section{Abbreviations}

NA: not available; HR: Hazard ratios; OS:overall survival; PFS:progression-free survival; DFS:disease-free survival; DSS:disease-specific survival; OSCC: oral squamous cell carcinoma; MTC: medullary thyroid carcinoma; NPC: nasopharyngeal carcinoma; ESCC: esophageal squamous cell carcinoma; cSCCHN: cutaneous squamous cell carcinoma of the head and neck; SGC: salivary gland carcinoma; HNSCC: head and neck squamous cell carcinoma; PTC: papillary thyroid cancer;Cl: Confidence interval; PD-1 and PD-L1: Programmed cell death protein-1 and ligand -1 ;

\section{Declarations}

\section{Acknowledgements}

We wish to thank everyone who helped with this study.

\section{Authors' contributions}

ZS designed the study, searched the literature, analysed and interpreted the data; LW and GZ performed the data entry, searched the literature, and wrote the manuscript; XC performed the data entry, searched the literature, and wrote the manuscript; DY searched the literature. All authors read and approved the final manuscript.

\section{Funding}

This study was funded by the Ningbo Health Branding Subject Fund (PPXK2018-02), the Natural Science Foundation of Zhejiang Province (LY14H160003), the Scientific Innovation Team Project of Ningbo (2012B82019, 2015B11050), the Ningbo Social Developmental Key Research Project (2012C5015), the Natural Science Foundation of Ningbo (2012A610217), the Medical and Health Research Project of Zhejiang Province (2012ZDA042), the Zhejiang Provincial Department of Health and Medicine Training Program (2014PYA017), the Natural Science Foundation of Ningbo (2013A610217ه2018A610361), the Leading and Top Talents Training Projects of Ningbo (NBLJ201801032)『and the Medical and Health Training Project of Zhejiang Province (2015RCB025).

Availability of data and materials

The datasets supporting the conclusions of this article are included within 
the article.

\section{Ethics approval and consent to participate}

Not applicable.

\section{Consent for publication}

Not applicable.

\section{Competing interests}

The authors declare that they have no competing interests.

\section{Author details}

${ }^{1}$ Department of Otorhinolaryngology Head and Neck Surgery, Ningbo Medical Center Lihuili Hospital, Ningbo University, Zhejiang,Ningbo, China. ${ }^{2}$ Laboratory of Otorhinolaryngology Head and Neck Surgery, Ningbo Medical Center Lihuili Hospital, Ningbo University, Zhejiang, Ningbo, China. ${ }^{3}$ Department of Gastrointestinal Surgery, Ningbo Medical Center Lihuili Hospital, Ningbo University, Zhejiang,Ningbo, China. ${ }^{4}$ Ningbo Medical Center Lihuili Hospital, Ningbo University, Zhejiang, Ningbo, China.

\section{References}

1.Argiris A, Karamouzis MV, Raben D, Ferris RL. Head and neck cancer. Lancet 2008;371(9625):1695-1709.

2.Fitzmaurice C, Allen C, Barber RM, Barregard L, Bhutta ZA, Brenner H, Dicker DJ, Chimed-Orchir O, Dandona R, Dandona L, et al. Global, Regional, and National Cancer Incidence, Mortality, Years of Life Lost, Years Lived With Disability, and Disability-Adjusted Life-years for 32 Cancer Groups, 1990 to 2015: A Systematic Analysis for the Global Burden of Disease Study. JAMA Oncol 2017;3(4):524-548.

3.Sturgis EM, Cinciripini PM. Trends in head and neck cancer incidence in relation to smoking prevalence: an emerging epidemic of human papillomavirus-associated cancers? Cancer 2007;110(7):1429-1435.

4.Reynoso ED, Elpek KG, Francisco L, Bronson R, Bellemare-Pelletier A, Sharpe AH, Freeman GJ, Turley SJ.. Intestinal tolerance is converted to autoimmune enteritis upon PD-1 ligand blockade. J Immunol 2009;182(4):2102-2112.

5.Patsoukis N, Bardhan K, Chatterjee P, Sari D, Liu B, Bell LN, Karoly ED, Freeman GJ, Petkova V1, Seth P,et al.PD-1 alters T-cell metabolic reprogramming by inhibiting glycolysis and promoting lipolysis and fatty acid oxidation. Nat Commun 2015;6:6692.

6.Li Y1, Li F, Jiang F, Lv X, Zhang R, Lu A, Zhang G. A Mini-Review for Cancer Immunotherapy: Molecular Understanding of PD-1/PD-L1 Pathway \&amp; Translational Blockade of Immune Checkpoints. Int J Mol Sci 2016;17(7). 
7.Müller T, Braun M, Dietrich D, Aktekin S, Höft S, Kristiansen G, Göke F, Schröck A, Brägelmann J, Held SAE, et al. PD-L1: a novel prognostic biomarker in head and neck squamous cell carcinoma. Oncotarget 2017;8(32):52889-52900.

8.Stang A. Critical evaluation of the Newcastle-Ottawa scale for the assessment of the quality of nonrandomized studies in meta-analyses. Eur J Epidemiol 2010;25(9):603-605.

9. Ioannidis JP, Trikalinos TA. The appropriateness of asymmetry tests for publication bias in meta-analyses: a large survey. CMAJ 2007;176(8):1091-1096.

10.Ahn H, Yang JM, Kim H, Chung JH, Ahn SH, Jeong WJ, Paik JH. Clinicopathologic implications of the miR-197/PD-L1 axis in oral squamous cell carcinoma. Oncotarget 2017;8(39):66178-66194.

11.Bi Y, Ren X, Bai X, Meng Y, Luo Y, Cao J, Zhang Y, Liang Z.PD-1/PD-L1 expressions in medullary thyroid carcinoma: Clinicopathologic and prognostic analysis of Chinese population. Eur J Surg Oncol 2019;45(3):353-358.

12.Chang AMV, Chiosea SI, Altman A, Pagdanganan HA, Ma C. Programmed Death-Ligand 1 Expression, Microsatellite Instability, Epstein-Barr Virus, and Human Papillomavirus in Nasopharyngeal Carcinomas of Patients from the Philippines. Head Neck Pathol 2017;11(2):203-211.

13.Chen K, Cheng G, Zhang F, Zhang N, Li D, Jin J, Wu J, Ying L, Mao W, Su D.Prognostic significance of programmed death-1 and programmed death-ligand 1 expression in patients with esophageal squamous cell carcinoma. Oncotarget 2016;7(21):30772-30780.

14.Chen TC, Wu CT, Wang CP, Hsu WL, Yang TL, Lou PJ, Ko JY, Chang YL. Associations among pretreatment tumor necrosis and the expression of HIF-1a and PD-L1 in advanced oral squamous cell carcinoma and the prognostic impact thereof. Oral Oncol 2015;51(11):1004-1010.

15.De Vicente JC, Rodríguez-Santamarta T, Rodrigo JP, Blanco-Lorenzo V, Allonca E, García-Pedrero JM. PDL1 expression in tumor cells is an independent unfavorable prognostic factor in oral squamous cell carcinoma. Cancer Epidemiol Biomarkers Prev 2019;28(3):546-554.

16.García-Pedrero JM, Martínez-Camblor P, Diaz-Coto S, Munguia-Calzada P, Vallina-Alvarez A, VazquezLopez F, Rodrigo JP, Santos-Juanes J.Tumor programmed cell death ligand 1 expression correlates with nodal metastasis in patients with cutaneous squamous cell carcinoma of the head and neck. J Am Acad Dermatol 2017;77(3):527-533.

17. Hatogai K, Fujii S, Kojima T, Daiko H, Nomura S, Doi T, Kitano S, Ohtsu A, Takiguchi Y, Yoshino T,et al. Large-scale comprehensive immunohistochemical biomarker analyses in esophageal squamous cell carcinoma. J Cancer Res Clin Oncol 2017;143(11):2351-2361.

18.Kim R, Keam B, Kwon D, Ock CY, Kim M, Kim TM, Kim HJ, Jeon YK, Park IK, Kang CH, et al. Programmed death ligand-1 expression and its prognostic role in esophageal squamous cell carcinoma. World J Gastroenterol 2016;22(37):8389-8397. 
19.Kim HS, Lee JY, Lim SH, Park K, Sun JM, Ko YH, Baek CH, Son YI, Jeong HS, Ahn YC, et al. Association Between PD-L1 and HPV Status and the Prognostic Value of PD-L1 in Oropharyngeal Squamous Cell Carcinoma. Cancer Res Treat 2016;48(2):527-536.

20.Li YF, Ding JW, Liao LM, Zhang ZL, Liao SS, Wu Y, Zhou DY, Liu AW, Huang L. Expression of programmed death ligand-1 predicts poor outcome in nasopharyngeal carcinoma. Mol Clin Oncol 2017;7(3):378-382.

21.Lim SH, Hong M, Ahn S, Choi YL, Kim KM, Oh D, Ahn YC, Jung SH, Ahn MJ, Park K, et al. Changes in tumour expression of programmed death-ligand 1 after neoadjuvant concurrent chemoradiotherapy in patients with squamous oesophageal cancer. Eur J Cancer 2016;52:1-9.

22.Lin YM, Sung WW, Hsieh MJ, Tsai SC, Lai HW, Yang SM, Shen KH, Chen MK, Lee H, Yeh KT,et al. High PDL1 Expression Correlates with Metastasis and Poor Prognosis in Oral Squamous Cell Carcinoma. Plos one 2015;10(11):e0142656.

23.Liu YJ, Tsang NM, Hsueh C, Yeh CJ, Ueng SH, Wang TH, Chuang WY. Low PD-L1 Expression Strongly Correlates with Local Recurrence in Epstein-Barr Virus-Positive Nasopharyngeal Carcinoma after RadiationBased Therapy. Cancers (Basel) 2018;10(10).

24.Loos M, Langer R, Schuster T, Gertler R, Walch A, Rauser S, Friess H, Feith M.Clinical significance of the costimulatory molecule B7-H1 in Barrett carcinoma. Ann Thorac Surg 2011;91(4):1025-1031.

25.Mukaigawa T, Hayashi R, Hashimoto K, Ugumori T, Hato N, Fujii S. Programmed death ligand-1 expression is associated with poor disease free survival in salivary gland carcinomas. J Surg Oncol 2016;114(1):36-43.

26.Ngamphaiboon N, Chureemas T, Siripoon T, Arsa L, Trachu N, Jiarpinitnun C, Pattaranutaporn P, Sirachainan E, Larbcharoensub N.Characteristics and impact of programmed death-ligand 1 expression, CD8+ tumor-infiltrating lymphocytes, and p16 status in head and neck squamous cell carcinoma. Med Oncol 2019;36(2):21.

27. Oliveira-Costa JP, de Carvalho AF, da Silveira da GG, Amaya P, Wu Y, Park KJ, Gigliola MP, Lustberg M, Buim ME, Ferreira EN, et al. Gene expression patterns through oral squamous cell carcinoma development: PD-L1 expression in primary tumor and circulating tumor cells. Oncotarget 2015;6(25):20902-20920.

28.Rong L, Liu Y, Hui Z, Zhao Z, Zhang Y, Wang B, Yuan Y, Li W, Guo L, Ying J, et al. PD-L1 expression and its clinicopathological correlation in advanced esophageal squamous cell carcinoma in a Chinese population. Diagn Pathol 2019;14(1):6.

29.Shi RL, Qu N, Luo TX, Xiang J, Liao T, Sun GH, Wang Y, Wang YL, Huang CP, Ji QH. Programmed DeathLigand 1 Expression in Papillary Thyroid Cancer and Its Correlation with Clinicopathologic Factors and Recurrence. Thyroid 2017;27(4):537-545.

30.Tanaka K, Miyata H, Sugimura K, Kanemura T, Hamada-Uematsu M, Mizote Y, Yamasaki M, Wada $\mathrm{H}$, Nakajima K, Takiguchi S,et al. Negative influence of programmed death-1-ligands on the survival of 
esophageal cancer patients treated with chemotherapy. Cancer Sci 2016;107(6):726-733.

31.Lee VH, Lo AW, Leung CY, Shek WH, Kwong DL, Lam KO, Tong CC, Sze CK, Leung TW. Correlation of PDL1 Expression of Tumor Cells with Survival Outcomes after Radical Intensity-Modulated Radiation Therapy for Non-Metastatic Nasopharyngeal Carcinoma. PloS one 2016;11(6):e0157969.

32. Yang F, Zeng Z, Li J, Zheng Y, Wei F, Ren X. PD-1/PD-L1 Axis, Rather Than High-Mobility Group Alarmins or CD8+ Tumor-Infiltrating Lymphocytes, Is Associated with Survival in Head and Neck Squamous Cell Carcinoma Patients Who Received Surgical Resection.Front Oncol 2018;11(8):604.

33.Zheng L, Cao C, Cheng G, Hu Q, Chen X. Cytomembranic PD-L1 expression in locoregionally advanced nasopharyngeal carcinoma. Onco Targets Ther 2017;10:5483-5487.

34.Zhou Y, Miao J, Wu H, Tang H, Kuang J, Zhou X, Peng Y, Hu D, Shi D, Deng W,et al. PD-1 and PD-L1 expression in 132 recurrent nasopharyngeal carcinoma: the correlation with anemia and outcomes. Oncotarget 2017;8(31):51210-51223.

35.Zhu Q, Cai MY, Chen CL, Hu H, Lin HX, Li M, Weng DS, Zhao JJ, Guo L, Xia JC. Tumor cells PD-L1 expression as a favorable prognosis factor in nasopharyngeal carcinoma patients with pre-existing intratumor-infiltrating lymphocytes. Oncoimmunology 2017;6(5):e1312240.

36. Wang Q, Liu F, Liu L. Prognostic significance of PD-L1 in solid tumor: An updated meta-analysis. Medicine 2017;96(18):e6369.

37.Xue S, Song G, Yu J. The prognostic significance of PD-L1 expression in patients with glioma: A metaanalysis. Sci Rep 2017;7(1):4231.

38.Wang Z, Peng S, Xie H, Guo L, Cai Q, Shang Z, Jiang N, Niu Y. Prognostic and clinicopathological significance of PD-L1 in patients with renal cell carcinoma: a meta-analysis based on 1863 individuals. Clin Exp Med 2018;18(2):165-175.

39.Petrelli F, Maltese M, Tomasello G, Conti B, Borgonovo K, Cabiddu M, Ghilardi M, Ghidini M, Passalacqua $\mathrm{R}$, Barni S,et al. Clinical and molecular predictors of PD-L1 expression in non small cell lung cancer: $A$ systematic review and meta-analysis. Clin Lung Cancer 2018;19(4): 315-322..

40.Yang WF, Wong MCM, Thomson PJ, Li KY, Su YX.. The prognostic role of PD-L1 expression for survival in head and neck squamous cell carcinoma: A systematic review and meta-analysis. Oral Oncol 2018;86:8190 .

\section{Tables}

Table 1. Characteristics of the studies included for meta-analysis 


\begin{tabular}{|c|c|c|c|c|c|c|c|c|}
\hline First Author & Year & Country & $\begin{array}{l}\text { sample } \\
\text { size }\end{array}$ & $\begin{array}{l}\text { Survival } \\
\text { Results }\end{array}$ & $\begin{array}{l}\text { Cut-off } \\
\text { Value for } \\
\text { PD-L1 } \\
\text { Positivity }\end{array}$ & $\begin{array}{l}\text { Cancer } \\
\text { Type }\end{array}$ & $\begin{array}{l}P \\
\text { value }\end{array}$ & $\begin{array}{l}\text { NOS } \\
\text { Score }\end{array}$ \\
\hline Ahn $\mathrm{H}$ & 2017 & Korea & 68 & OS & NA & OSCC & 0.039 & 5 \\
\hline $\mathrm{Bi} Y$ & 2018 & China & 87 & OS & $1 \%$ & MTC & 0.083 & 6 \\
\hline Chang AMV & 2016 & Philippines & 56 & OS & $5 \%$ & NPC & 0.801 & 6 \\
\hline Chen TC & 2015 & Taiwan & 218 & OS & $5 \%$ & OSCC & 0.97 & 8 \\
\hline Chen $\mathrm{K}$ & 2016 & China & 536 & OS & $5 \%$ & ESCC & 0.293 & 7 \\
\hline de Vicente JC & 2018 & Spain & 125 & DSS & $10 \%$ & OSCC & 0.01 & 6 \\
\hline $\begin{array}{l}\text { García-Pedrero } \\
\text { JM }\end{array}$ & 2017 & Spain & 100 & OS & $1 \%$ & $\mathrm{cSCCHN}$ & 0.29 & 6 \\
\hline Hatogai K & 2017 & Japan & 286 & OS & $1 \%$ & ESCC & 0.015 & 6 \\
\hline Kim HS & 2015 & Korea & 133 & OS & $5 \%$ & OSCC & 0.513 & 7 \\
\hline Kim R & 2016 & $\begin{array}{l}\text { South } \\
\text { Korea }\end{array}$ & 200 & OS & $\mathrm{H}$-score & ESCC & 0.034 & 6 \\
\hline Li YF & 2017 & China & 62 & DFS & $20 \%$ & NPC & 0.006 & 6 \\
\hline Lim SH & 2016 & $\begin{array}{l}\text { South } \\
\text { Korea }\end{array}$ & 73 & OS & $\mathrm{H}$-score & ESCC & 0.023 & 6 \\
\hline Lin YM & 2015 & Taiwan & 305 & OS & NA & oscc & 0.0609 & 7 \\
\hline Liu YJ & 2018 & Taiwan & 208 & OS & $4 \%$ & NPC & 0.15 & 6 \\
\hline Loos M & 2011 & Germany & 101 & OS & NA & ESCC & $\begin{array}{l}\mathrm{p}< \\
0.001\end{array}$ & 6 \\
\hline Mukaigawa T & 2016 & Japan & 219 & OS & $1 \%$ & SGC & 0.459 & 6 \\
\hline Ngamphaiboon & 2019 & Thailand & 203 & OS & $5 \%$ & HNSCC & 0.505 & 7 \\
\hline $\begin{array}{l}\text { Oliveira-Costa } \\
\text { JP }\end{array}$ & 2015 & Brazil & 142 & OS & $5 \%$ & OSCC & 0.27 & 6 \\
\hline Rong L & 2019 & China & 378 & OS & $1 \%$ & ESCC & 0.423 & 7 \\
\hline Shi RL & 2017 & China & 260 & RFS & NA & PTC & 0.024 & 6 \\
\hline Tanaka K & 2016 & Japan & 180 & os & NA & ESCC & 0.011 & 6 \\
\hline Victor H.F. Lee & 2016 & $\begin{array}{l}\text { Hong } \\
\text { Kong }\end{array}$ & 104 & OS & $5 \%$ & NPC & 0.261 & 6 \\
\hline Yang F & 2018 & China & 81 & OS & NA & HNSCC & 0.002 & 6 \\
\hline Zheng L & 2017 & China & 85 & OS & $\mathrm{H}$-score & NPC & 0.032 & 6 \\
\hline Zhou Y & 2017 & China & 132 & $\begin{array}{l}\text { OS } \\
11 / 18\end{array}$ & $\mathrm{H}$-score & NPC & 0.016 & 7 \\
\hline
\end{tabular}


OS

$5 \%$

NPC

0.693

7

Abbreviations: NA, not available; OS, overall survival; PFS, progression-free survival; DFS, disease-free survival; DSS, disease-specific survival; OSCC, oral squamous cell carcinoma; MTC, medullary thyroid carcinoma; NPC, nasopharyngeal carcinoma; ESCC, esophageal squamous cell carcinoma; cSCCHN, cutaneous squamous cell carcinoma of the head and neck; SGC, salivary gland carcinoma; HNSCC, head and neck squamous cell carcinoma; PTC, papillary thyroid cancer.

\section{Figures}




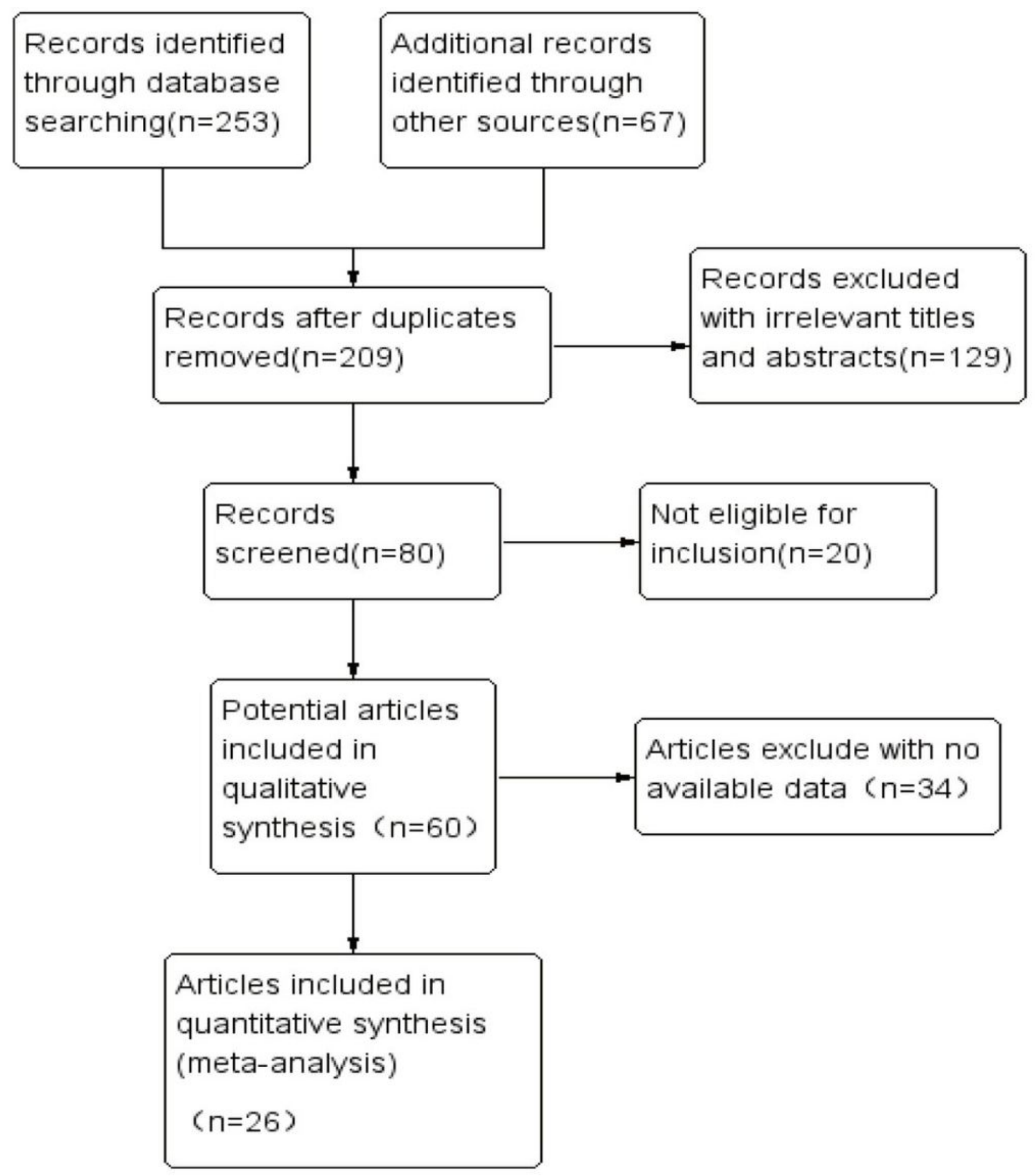

Figure 1

Flow chart of the study selection. 
Hazard Ratio

Study or Subgroup log[Hazard Ratio]
$-1.139$

Bi2018

Chang2016

Chen2015

Chen2016

de Vicente2018

Garcia2017

Hatogai2017

Kim2015

Kim2016

Li2017

Lim2016

Lin2015

Liu 2018

Loos2011

Mukaigawa 2016

Ngamphaiboon2019

Oliveira2015

Rong2019

Shi2017

Tanaka2016

Victor2016

Yang2018

Zheng2017

Zhou2017

Zhu2017
$1.275-0.734-3.0 \%$

$\begin{array}{lll}-0.252 & 1.002 \quad 1.4 \%\end{array}$

$0.01 \quad 0.1871 \quad 5.1 \%$

$\begin{array}{lll}-0.1863 & 0.1741 \quad 5.2 \%\end{array}$

$2.5710 .4017 \quad 3.8 \%$

$\begin{array}{lll}0.3784 & 0.3607\end{array}$

$\begin{array}{ll}-0.5798 & 0.2398\end{array}$

$\begin{array}{lll}-0.3595 & 0.5496\end{array}$

$\begin{array}{ll}-0.5276 & 0.2521\end{array}$

$\begin{array}{lll}-1.814 & 0.6682\end{array}$

$\begin{array}{lll}0.8286 & 0.3644\end{array}$

$0.2964 \quad 0.1579$

$0.392 \quad 0.2711$

$\begin{array}{lll}1.2528 & 0.3806\end{array}$

$\begin{array}{ll}0.27 & 0.3817\end{array}$

$\begin{array}{lll}0.157 & 0.2337\end{array}$

$0.967 \quad 0.8766$

$\begin{array}{ll}-0.1256 & 0.1573\end{array}$

$\begin{array}{ll}1.0385 & 0.459\end{array}$

$0.5585 \quad 0.2194$

$-0.5516 \quad 0.4911$

$\begin{array}{lll}-1.2413 & 0.3998\end{array}$

1.82070 .8506

$\begin{array}{ll}-0.6368 & 0.2645\end{array}$

$0.1098 \quad 0.2781$

$4.1 \%$

$4.8 \%$

$3.0 \%$

$4.8 \%$

$2.4 \%$

$4.0 \%$

$5.3 \%$

$4.6 \%$

$3.9 \%$

$3.9 \%$

$4.9 \%$

$1.7 \%$

$5.3 \%$

$3.5 \%$

$4.9 \%$

$3.3 \%$

$3.8 \%$

$1.8 \%$

$4.7 \%$

$4.6 \%$
Hazard Ratio

IV, Random, $95 \% \mathrm{Cl}$

Total $(95 \% \mathrm{Cl})$

$100.0 \% \quad 1.15[0.88,1.50]$

Heterogeneity: $\mathrm{Tau}^{2}=0.34 ; \mathrm{Chi}^{2}=124.64, \mathrm{df}=25(\mathrm{P}<0.00001) ; \mathrm{I}^{2}=80 \%$

Test for overall effect: $Z=1.00(P=0.32)$
$0.32[0.11,0.93]$

$3.58[0.85,15.08]$

$0.78[0.11,5.54]$

$1.01[0.70,1.46]$

$0.83[0.59,1.17]$

$13.08[5.95,28.74]$

$1.46[0.72,2.96]$

$0.56[0.35,0.90]$

$0.70[0.24,2.05]$

$0.59[0.36,0.97]$

$0.16[0.04,0.60]$

$2.29[1.12,4.68]$

$1.35[0.99,1.83]$

$1.48[0.87,2.52]$

$3.50[1.66,7.38]$

$1.31[0.62,2.77]$

$1.17[0.74,1.85]$

$2.63[0.47,14.66]$

$0.88[0.65,1.20]$

$2.82[1.15,6.95]$

$1.75[1.14,2.69]$

$0.58[0.22,1.51]$

$0.29[0.13,0.63]$

$6.18[1.17,32.72]$

$0.53[0.31,0.89]$

$1.12[0.65,1.92]$

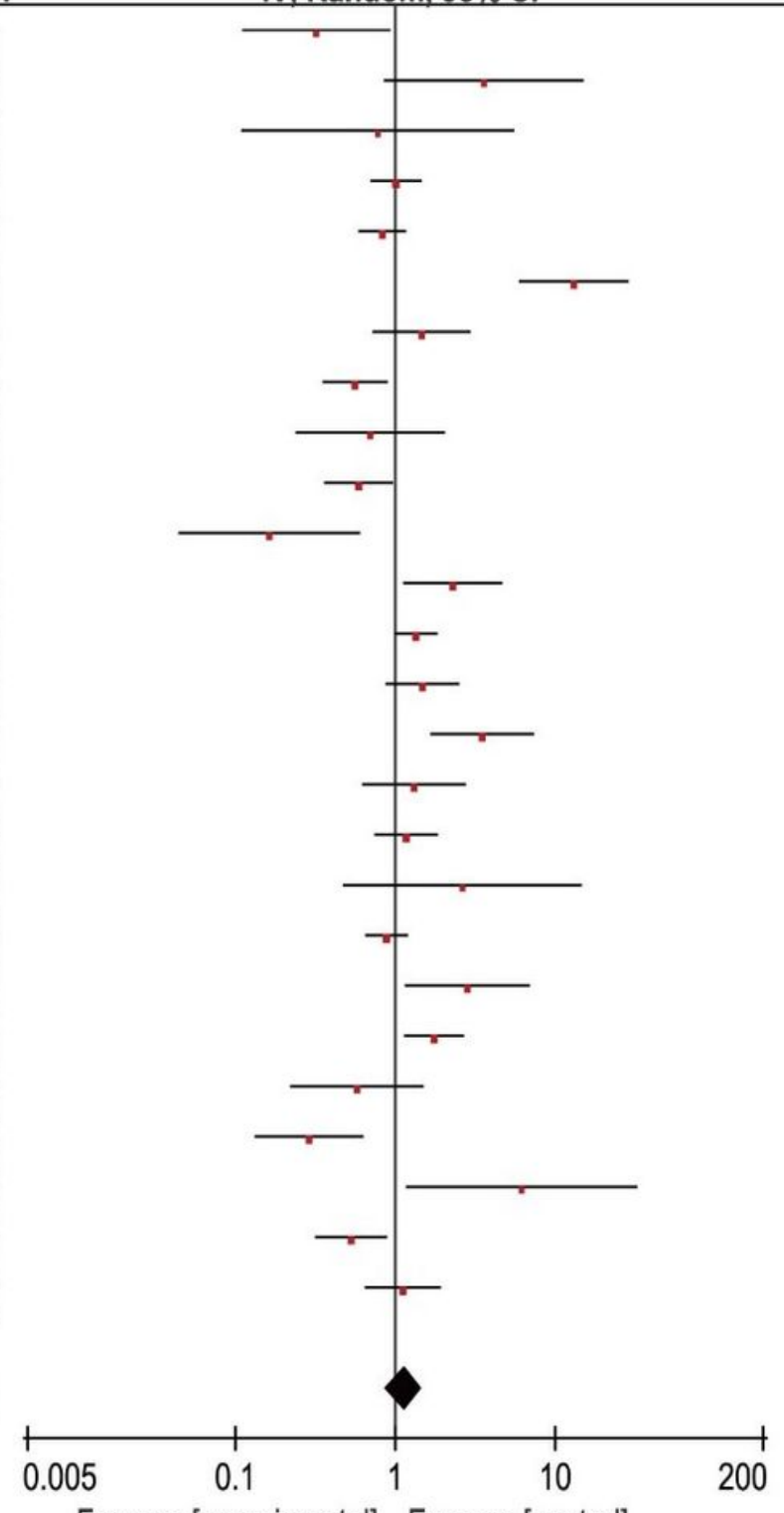

Favours [experimental] Favours [control]

\section{Figure 2}

Forest plot describing the association between PD-L1 expression and HR of patients with HNC. 


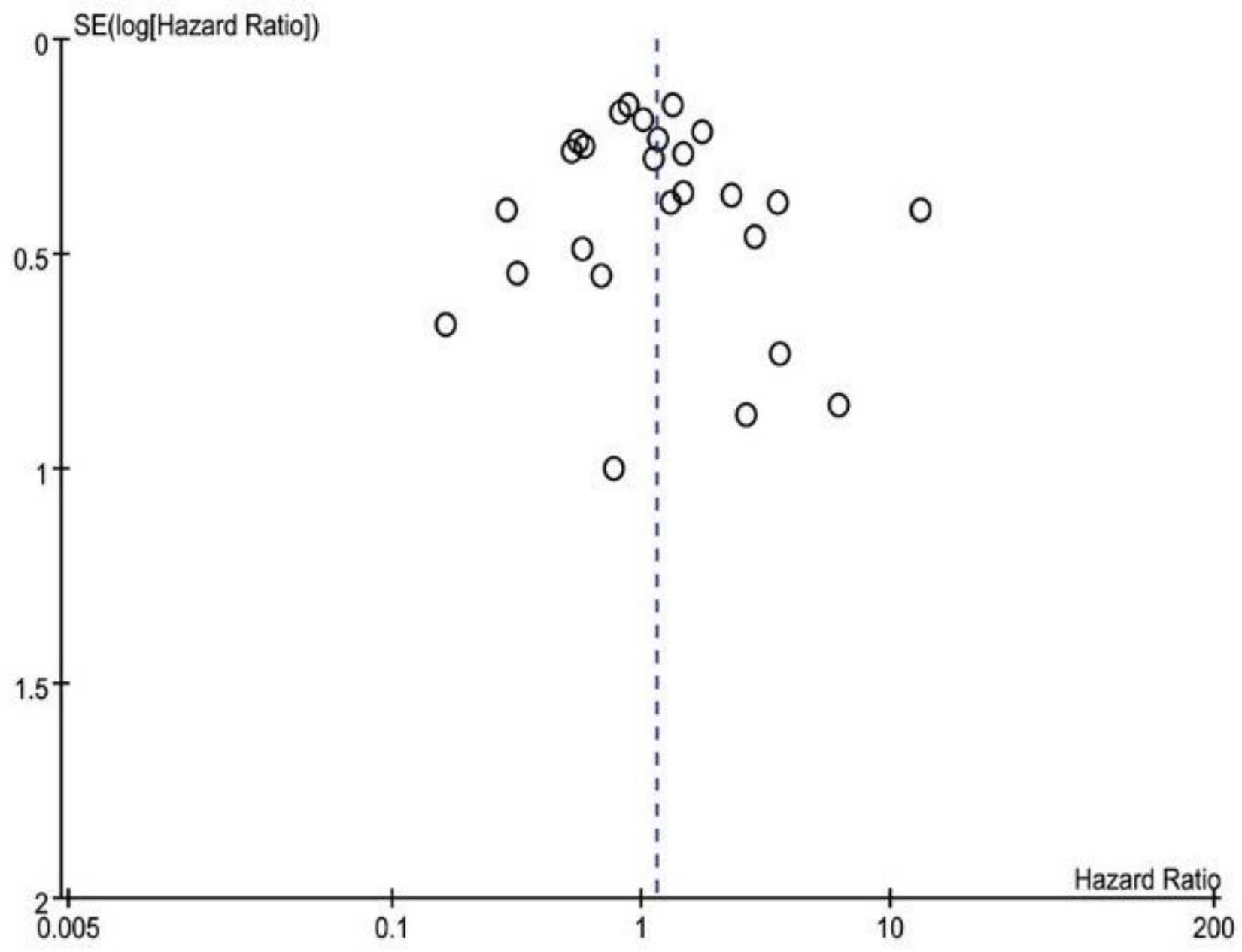

Figure 3

Meta-analysis forest plot of the subgroups of HNC survival in different regions. 


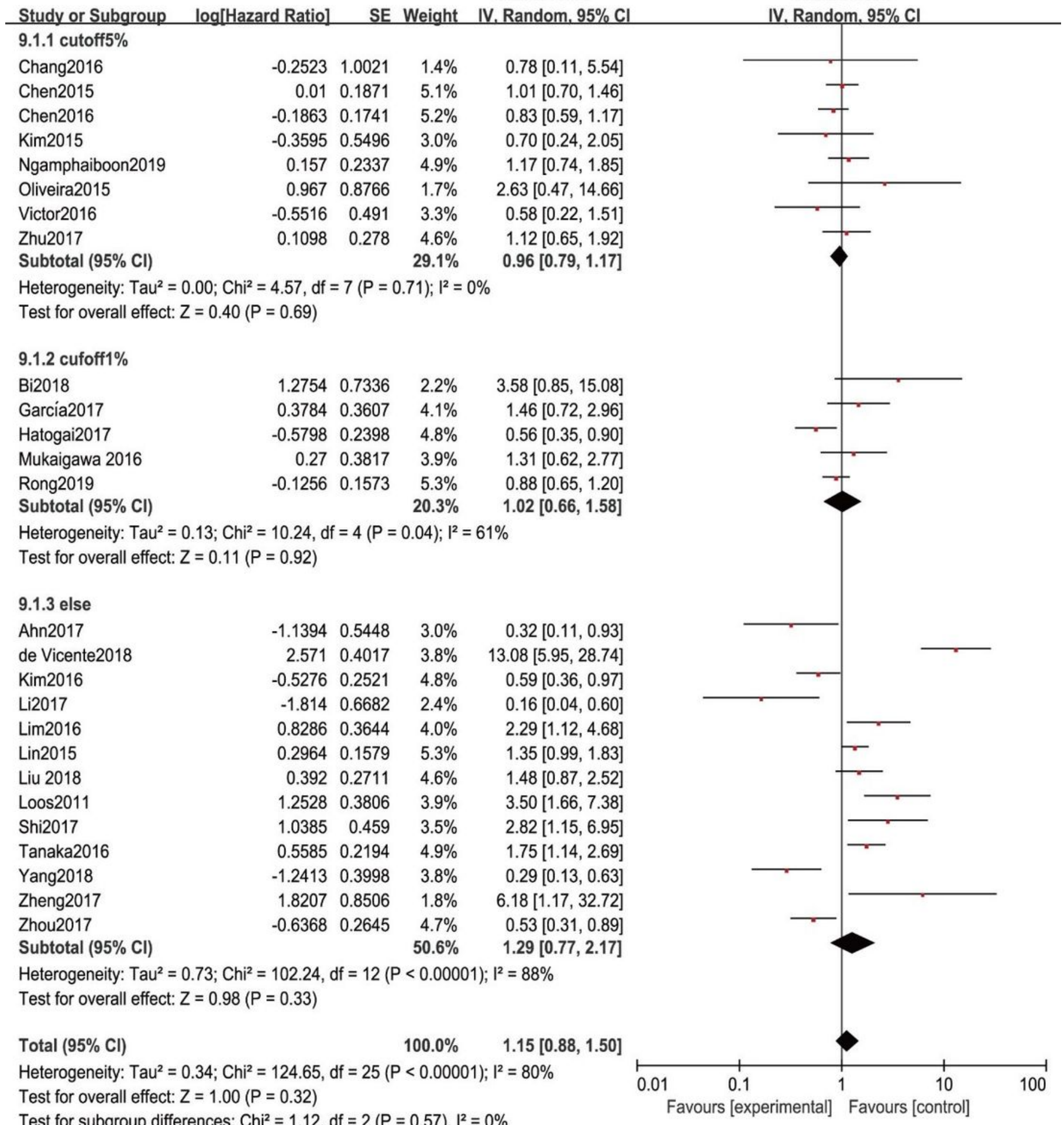

\section{Figure 4}

Meta-analysis forest plots of the survival subgroups of HNC with different cutoffs. 
Hazard Ratio

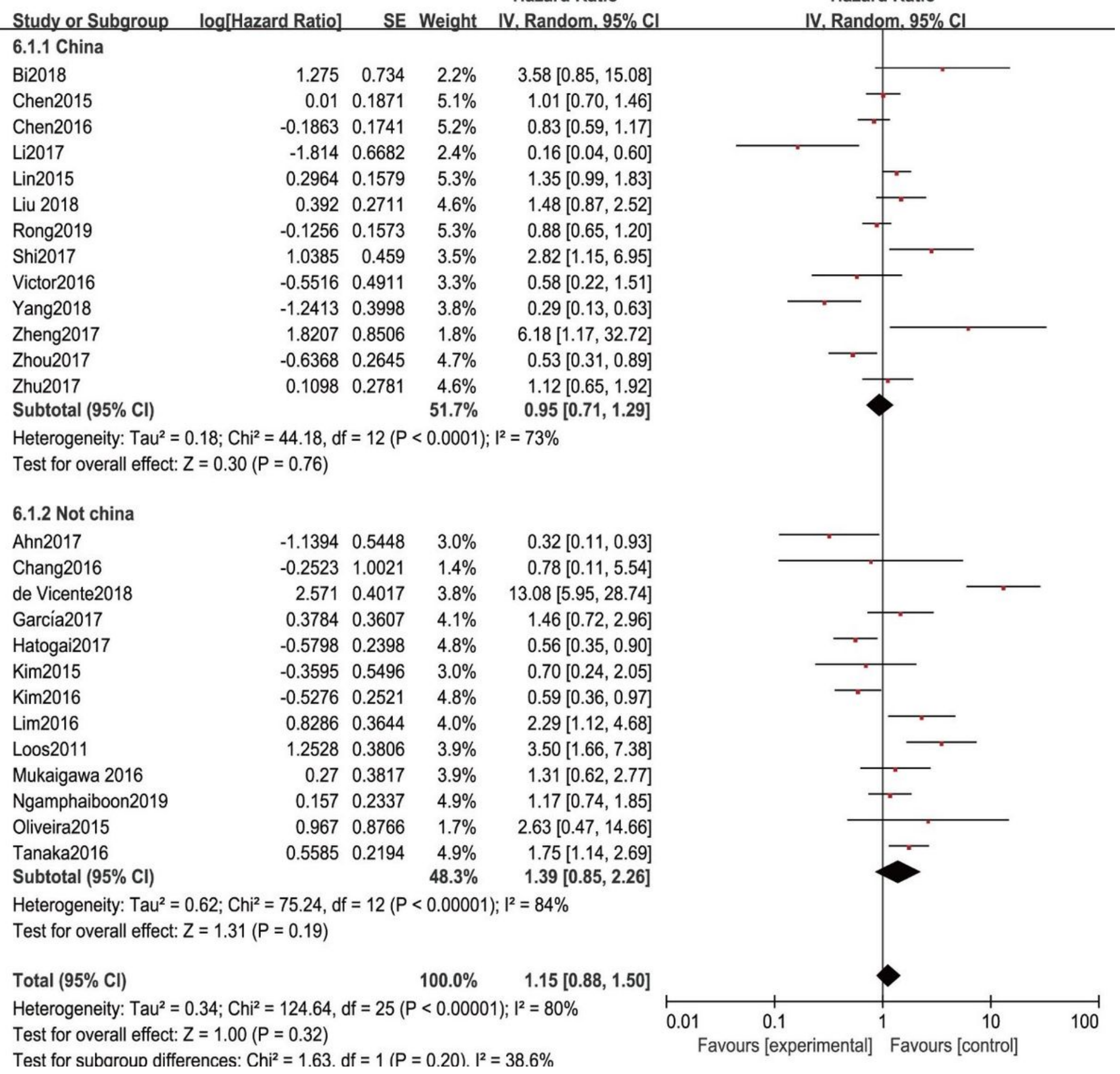

\section{Figure 5}

Meta-analysis forest plots of the survival subgroups of different types of HNC. 


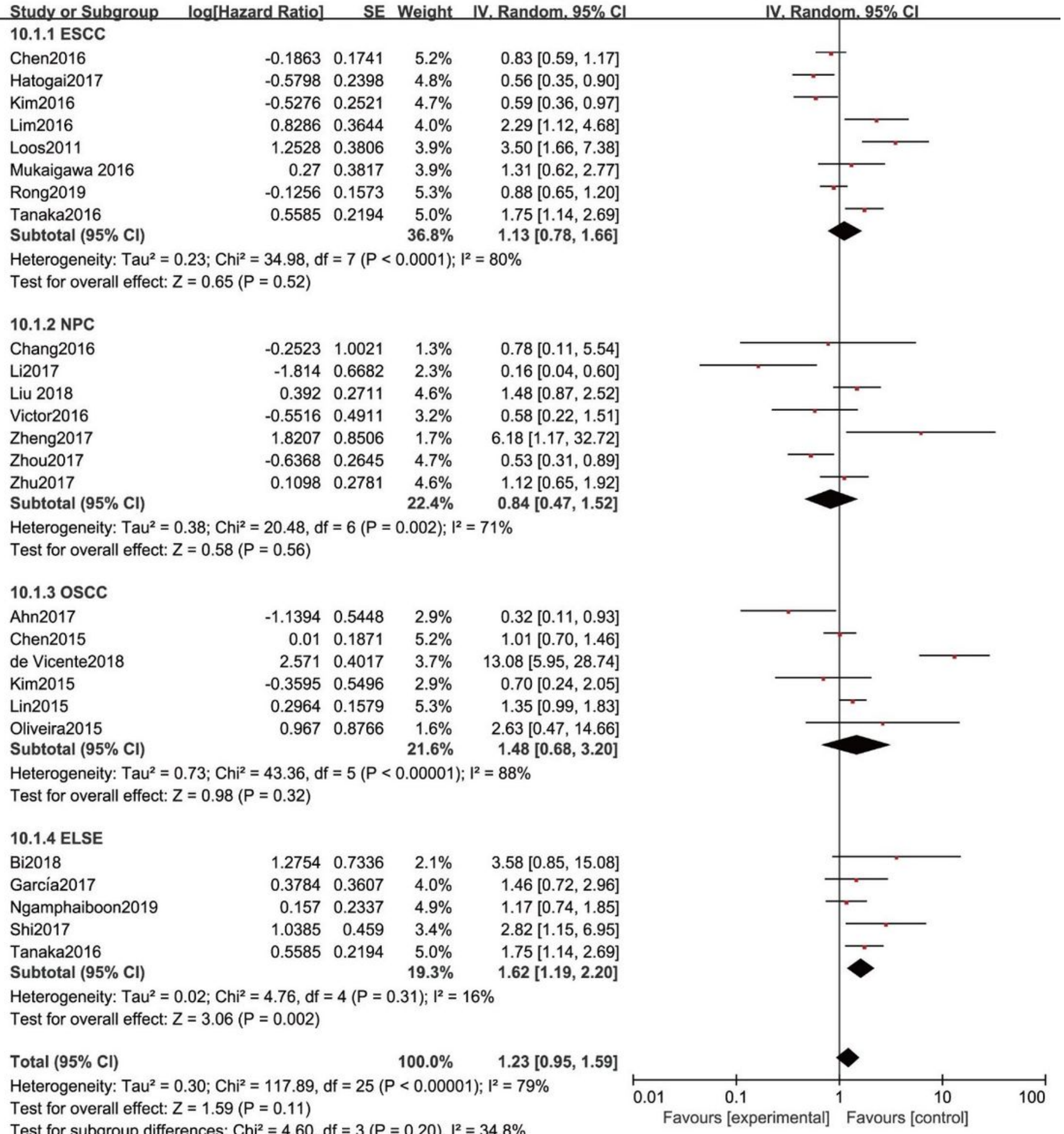

\section{Figure 6}

The funnel plot test evaluating the publication bias. 